\title{
Methods for Assessing Meteorological and Hydrological Risk in the Aspect of Changes in the Natural Environment
}

\author{
Leszek Kuchar
}

Wroclaw University of Environmental and Life Science, 50357, Wroclaw, Poland

doi: https://doi.org/10.21467/abstracts.93.27

\begin{abstract}
In the natural environment of humans there is a variability of phenomena that is accompanied by the risk of rare events. In mathematical modeling, these are the events that occur on the tails of the probability distributions of random variables associated with a given phenomenon. In this case, if we can determine the probability distributions, then indicating the risk is not very difficult and requires reading the quantiles of the probability distribution. However, the problem of determining the probability distribution is well known and widely described in the literature for a very long time. Nevertheless, it is still valid especially when properly estimating distribution quantiles.

Regardless of the above problem, when the phenomenon is accompanied by natural variation, there may be a situation of change (e.g. forced change) of the phenomenon itself and its nature. In this case, random variables related to a given phenomenon may have a probability distribution and only its parameters changed, or these variables may have a completely different distribution. The situation described above can take place just in a situation of changing environment.

In mathematical modeling, a more complicated situation takes place when the distribution of random variables characterizing a given phenomenon is transformed by a mathematical model. This is actually a function of multiple random variables. In practice, the new distribution of the modeled random variable is difficult to determine analytically and it should be determined by the classic method as one-dimensional problem.
\end{abstract}

The above considerations is apply in determining the risk for meteorological and hydrological phenomena. In particular in modeling the effects of climate change, and river hydrology is a good example of determining risk in a changing environment. Particularly, projected changes in climate may have a potentially significant impact on the future hydrology in the river catchment, runoff response, and predictions. The daily runoff simulation, particularly seasonal extremes runoff in rivers are important for several reasons. The idea of runoff simulation in the river catchment for future climate conditions given by different scenarios are presented on the scheme below.

The simulations use generated values from random variable distributions using the weather generator SWGEN method. The SWGEN model generates precipitation by means of the first-order Markov chain to determine the occurrence of wet/dry days, and then for the amount of rainfall multidimensional twoparameter gamma distribution:

$$
\left(\Gamma_{\mathrm{m}}\left(\alpha_{1}, \beta_{1}\right), \ldots, \Gamma_{\mathrm{m}}\left(\alpha_{\mathrm{k}}, \beta_{\mathrm{k}}\right)\right)
$$

where $m$ is the number of months $(\mathrm{m}=1, \ldots, 12)$ and $k$ is the number of locations, while daily values of solar radiation $(\mathrm{SR})$, temperature maximum $\left(\mathrm{T}_{\max }\right)$ and minimum $\left(\mathrm{T}_{\mathrm{min}}\right)$ are considered as a multidimensional time series $\operatorname{AR}(1)$ in the following form:

$$
\mathrm{X}_{\mathrm{t}}=\Phi_{\mathrm{m}} \cdot \mathrm{X}_{\mathrm{t}-1}+\varepsilon_{\mathrm{t}}
$$

(C) 2020 Copyright held by the author(s). Published by AIJR Publisher in "Abstracts of The Second Eurasian RISK-2020 Conference and Symposium" April 12- 19, 2020, Tbilisi, Georgia. Jointly organized by AMIR Technical Services LLC, Georgian Technical University, Institute of Geography (Kazakhstan) and Russian Institute of Petroleum Geology and Geophysics.

AijR DOI: $10.21467 /$ abstracts. 93 
The Second Eurasian RISK-2020 Conference and Symposium

where $\mathrm{X}_{\mathrm{t}}$ and $\mathrm{X}_{\mathrm{t}-1}$ are vectors $(\mathrm{m} \times 1)$ of normalized values for all three variables for day $t$ and $t-1, \varepsilon_{\mathrm{t}}$ is a vector $(\mathrm{m} \times 1)$ of independent random components normally distributed with vector of mean equal to zero and matrix of covariance $\Sigma_{\mathrm{m}}$, and $\Phi_{\mathrm{m}}($ for $\mathrm{m}=1, \ldots, 12)$ is a matrix of parameters. As an example a new

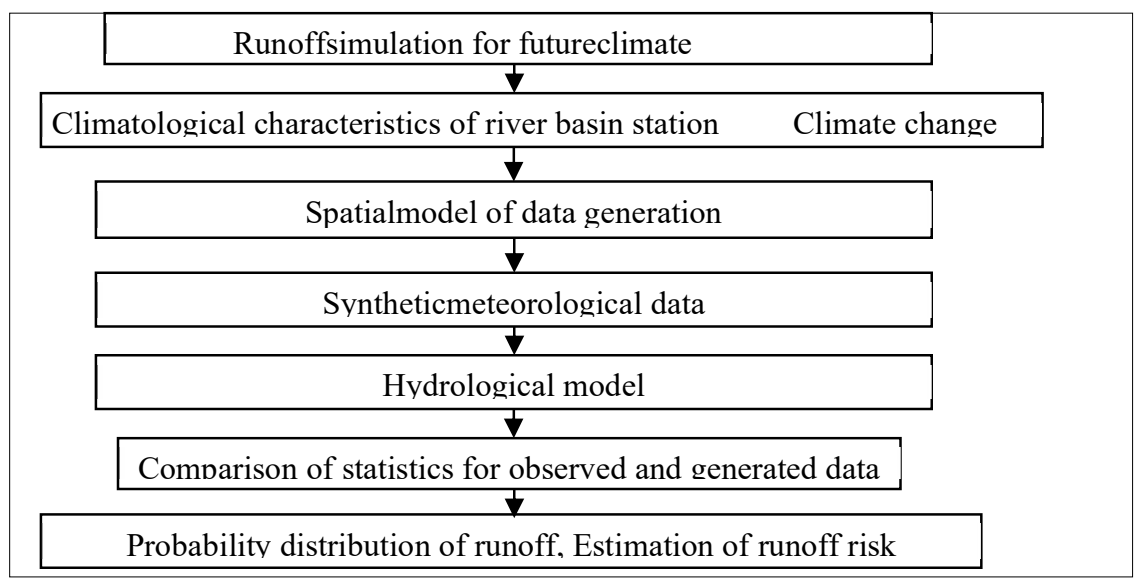

simulation of maximum and minimum daily flows for the Kaczawa River in south-west Poland and the year 2080 can be presented. The flow simulation in the river catchment was made using MIKE SHE hydrological model and long series of generated data for 24 sites of meteorological stations. Generated data as solar radiation, maximum temperature, minimum temperature and total rainfall were set up using spatial weather generator SWGEN producing the multisite daily time series based on 35 years of observed data gathered from the Institute of Meteorology and Water Management National Research Institute (IMGW).Data were generated for the present (the year 2000 are used as a background) as well for future climate condition for 2080 according Representative Concentration Pathways (RCPs) scenarios. The large number of new simulated series determined by the lead time, three climate change scenarios (RCP4.5, RCP6.0 and RCP8.5), and number of generated years (1000 for each case) is equal to 5000 for a single station. Finally, Lognormal pdf function for the maximum and minimum flows are presented as well probability of exceedance of $\max /$ min values.

The simulated maximum and minimum annual flows predicted for 2080 according to the averaged scenarios RCP4.5 and RCP6.0 are consistent with the maximum and minimum annual flows obtained for the SRES A1B scenarios (GISS Model E, HadCM3 and GFDL R15) in earlier studies. A 10-20 percent increase in the maximum and minimum annual daily flows in the case of significant water deficits in Poland is not a hydrological risk to the catchment of the Kaczawa River.

The long series of simulated years and the large number of stations used in calculations based on 35 years of observation allow us to believe that the simulations in flow changes in Kaczawa basin are reliable. The use of the hydrological rainfall-runoff model MIKE SHEtogether with the spatial weather generator SWGEN enables effective assessment of changes in flows in river basins with a long time horizon.

\section{References}

Chen J. Brissette F.P. Zhang X.C. 2014: A multi-site stochastic weather generator for daily precipitation and temperature. Trans. ASABE,57(5): 1375-1397.

Kuchar L. Iwanski S. Jelonek L. Szalinska W. 2015: A modeling framework to assess the impact of climate change in river runoff. Meteorol. Hydrol. Water Manag., 2(2): 49-63.

Wilks D.S. 2010: Use of stochastic weather generator for precipitation downscaling. Climate Change, 1: 898-907. 